\title{
LES で推定された建築物の空力特性の不確定性定量化 Uncertainty Quantification for Aerodynamic Characteristics in LES
}

\author{
浜田 翼*
}

Tsubasa HAMADA

\begin{abstract}
SUMMARY
With the development of computational power, CFD is becoming a promising tool for wind resistant design in industry. Although CFD is generally regarded as a deterministic exercise, wind-related phenomena and computational setting have many uncertainties. Hence, it is required to take uncertainty in CFD into account. The present paper shows a quantitative evaluation of impact of inflow uncertainty on wind load prediction. Firstly, to identify the magnitude of variability of wind loading, three types of grid resolution models are analyzed with five independent inflow conditions. In addition, we propose to use polynomial chaos to quantify analytically inflow uncertainty in wind load prediction. Wind load is largely changed with slight shift of wind angle. As a result, it is confirmed that importance of consideration on impact of uncertainty in CFD.
\end{abstract}

key words: Uncertainty quantification, Wind load prediction, Polynomial chaos, Grid sensitivity, LES

\section{1. はじめに}

近年の計算機能力の向上に伴い，建築物の耐風設計に おいて数值流体力学(CFD)の重要性が増しており実用化 が期待される. 一般に CFD は特定の入力条件のもとに 1 つの出力を与えるという意味で決定論的評価であり，不 確定性を考慮することが難しい。しかし，実現象の風や CFD のパラメータ設定には多くの不確定性が内在してお り決定論的よりも確率論的であり，実用化のためには CFD においても不確定性を考慮することが, 数值解の信 頼性の観点から重要である.

近年の不確定性解析では多項式カオス ${ }^{1)}$ に代表される, 少ないサンプルをもとに代理モデルを近似し不確定性定

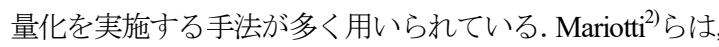
アスペクト比 5:1 の角柱の空力特性における流入条件の 不確定性定量化を実施し, 既往の実験や数值解のアンサ
ンブル平均と比較した. しかしながら，構造物の空力特 性における不確定性定量化に関する知見は非常に限られ ているのが現状である.

本研究では, まず CFD を用いた建築物の風荷重推定に おける不確定性の大きさを評価する.さらに格子解像度が 不確定性に与える影響も評価する．次に多項式カオスを 用い, 角柱と隅丸角柱の空力特性に対し, 風向角の変化 に対して出力が非線形的に変化する不確定性範囲を設定 し, 不確定性定量化を行う。また，そのような不確定性 範囲における多項式カオスの適用性も検証する.

\section{2. 格子解像度の変化が高層建築物の空力特性のばらつ きに与える影響の把握 \\ 本章では，異なる格子解像度の計算モデルごとに 5 波 の流入変動風における空力特性のばらつきの大きさと, 格子解像度が不確定性に与える影響を明らかにする。}

\footnotetext{
* 東京工業大学 環境・社会理工学院 建築学系 都市・環境学コース

School of Environment and Society, Tokyo Institute of Technology

(指導教員 田村哲郎 教授)
} 


\section{1 計算モデルと計算条件}

対象と寸る高層建築物は周辺市街地に囲まれており， 外装部材等まで詳細に再現されている（図 1)。風向角は 既往の研究 ${ }^{3}$ において実施された 72 風向の風洞実験から, 住宅棟に最小ピーク風力係数(Cp_min)が発生した風向角 $80^{\circ}$ を対象とした。格子解像度は 5 千万( $\left.50 \mathrm{M}\right), 1250$ 万 (12M) とし, 既往の研究における 2 億 (200M) と実験值 とそれぞれ比較した．ただし，これらの格子解像度の分 布は相似ではない.

本解析は非構造格子に基づく有限体積法ソルバー FrontFlow/Red を用いた. 支配方程式は, フィルター操作 を施した連続の式と Navier-Stokes 方程式である．時間積 分は SMAC 法による Euler 陰解法, 空間離散化は 2 次中 心である. 移流項には計算安定性確保のため 2 次中心項 に 1 次精度風上差分を $5 \%$ ブレンドした. SGS モデルは 標準 Smagorinsky(Cs=0.10)とし, 壁面付近では Van Driest 型の減衰関数を使用した.

流入境界において, 流入変動風は Jarrin ${ }^{4}$ らによる合成 渦法を用い既往の風洞実験 ${ }^{3)}$ で用いられた実験気流の值 をターゲットに 5 波作成し, 時・空間補間した流速をデ イリクレ条件として与えている. 流出境界においては速 度をノイマン条件で与え, 圧力はノイマン条件, および SMAC 法による圧力の補正係数に関してはディリクレ条 件で与えている. 側面と上面は Free-Slip 条件とした. た だし, 流入と流出境界では圧力の補正関数をゼロとした. 壁面と物体表面は壁関数の境界条件を与えた.

\section{2 数值解析結果とばらつきの大きさ}

図 2 に測定点 210 と 361 の各格子解像度における 5 波 の流入変動風における平均風圧係数と最小ピーク風圧係 数をプロットしている. 平均風圧係数は格子解像度によ って予測される值に傾向は見られるものの, 5 波のプロッ 卜の最大・最小のばらつき幅に大きな変化は見られない. しかしながら, 最小ピーク風圧係数では, 測定点 210 に おいて格子解像度の変化によってばらつきが大きく変化 していることが分かる. 一方, 測定点 361 では比較的ば らつきの幅は安定している. これは, 流れの変動が大き い隅角部か，比較的流れの安定している後流に測定点が 位置するかで大きく左右されると考えられる. 同様に,

図 3 に全体力係数の平均を示寸. 全ての係数においてば らつきの幅は安定している. 全体力は風圧係数の積分值 でり, ここではさらに時間の平均值であるため, 格子解 像度によるばらつきが小さくなったためと考えられる.

以上より, 格子解像度による空力特性のばらつきは, 測定点位置やその空力特性の性質 (平均值, ピーク值,
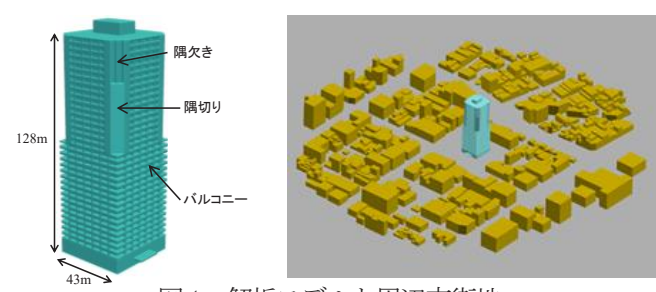

図 1 解析モデルと周辺市街地
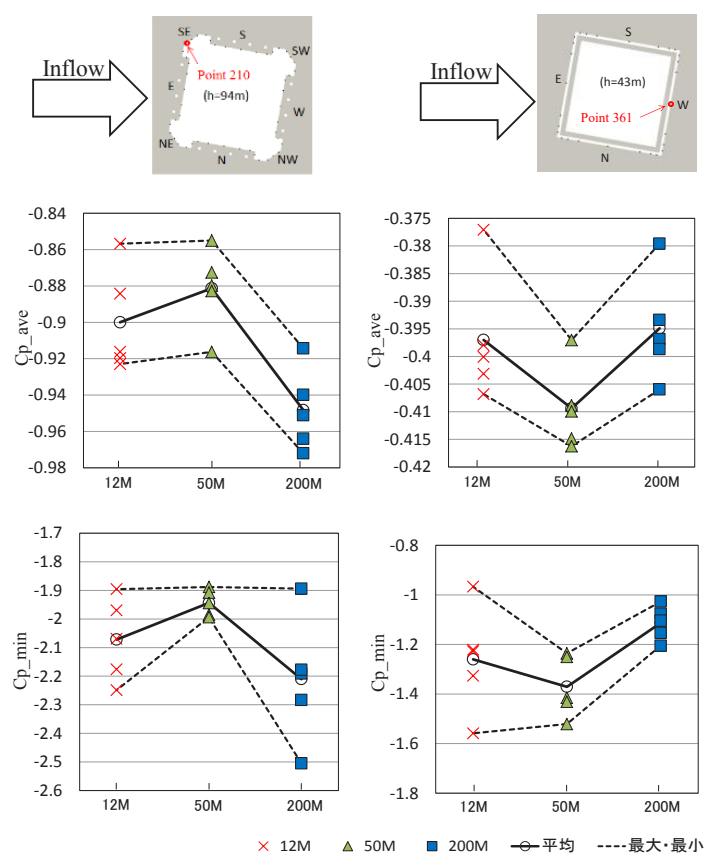

図 2 測定点 $210 ・ 361$ における風圧係数のばらつき

（上）平均風圧係数（下）最小ピーク風圧係数
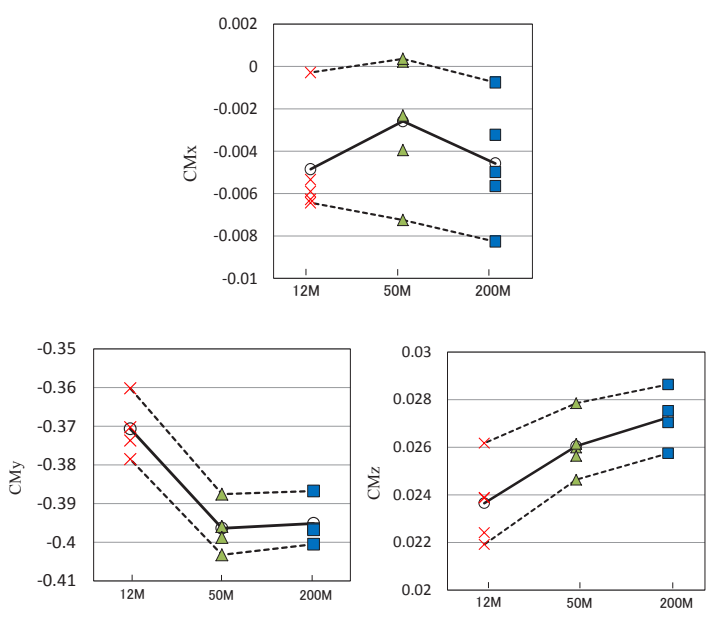

図 3 全体力係数のばらつき

（上）CMx_ave (左) CMy_ave (右) CMz_ave 
積分值）によって大きく変化することが確認された.

\section{3. 角柱と隅丸角柱の空力特性における不確定性定量化}

前章において流入のばらつきが建築物の空力特性に与 える影響は大きいことを確認した，そこで本章では建築 物の一般的な形状である角柱と隅丸角柱の空力特性に対 し，流入の不確定性が与える影響を定量的に明らかにす る. 近年の不確定性定量化の研究では, 応答局面法に分 類される少ないサンプルから代理モデル等を構築する多 項式力オス $(\mathrm{PC})^{1)}$ や Kriging ${ }^{5)}$ な゙が多く用いられ，その有 効性と適用性が報告されている ${ }^{67)}$. 本研究では計算コス 卜も低く，不確定性の影響の評価と同時に感度解析も容 易に実施できる PC を用い不確定性定量化を行う.

\section{1 多項式カオスと不確定性パラメータ}

PC では不確定な入力引に対する求めたい出力 Quantity of interest(QoI)の確率論的出力 $\mathrm{y}(t, \boldsymbol{x}, \boldsymbol{\xi})$ を以下のように多 項式展開する.

$$
\mathrm{y}(t, \boldsymbol{x}, \xi)=\sum_{i=0}^{N p-1} u_{i}(t, \boldsymbol{x}) \cdot \Psi_{i}(\xi)
$$

ここで, $u_{i}(t, \boldsymbol{x})$ は決定論的係数, $\Psi_{i}(\xi)$ は確率変数 $\boldsymbol{~}$ 直 交多項式数列, $N p$ は多項式の項数を表す. 直交多項式数 列は入力の不確定性の確率分布に基づき Wiener-Askey Scheme $(\mathrm{WSA})^{1)}$ より決まる. 決定論的係数を算出後, QoI の平均 $\mu$ と分散 $\sigma^{2}$ は以下のように容易に求めることがで きる.

$$
\sigma^{2}=\sum_{i=1}^{\substack{\mu=u_{0} \\ N p-1}}\left(u_{i}^{2} \Psi_{i}^{2}\right)
$$

また，得られた代理モデルに入力で仮定した不確定性範 囲内での乱数を与えることで QoI の確率分布を得ること もできる. さらに, 多項式カオスの直交関数の組み合わ せによって表現されるという Sobol 分解と同様の性質か ら, 以下のようの主 Sobol 係数 $S_{i}$ と交互 Sobol 係数 $S_{i j}$ を求 めることができる ${ }^{8}$.

$$
\begin{gathered}
S_{i}=\frac{\sigma^{2}\left[E\left(u \mid \xi_{i}\right)\right]}{\sigma^{2}(u)} \\
S_{i j}=\frac{\sigma^{2}\left[E\left(u \mid \xi_{i}, \xi_{j}\right)\right]}{\sigma^{2}(u)}
\end{gathered}
$$

Sobol 係数は, 出力のバラつきに対して入力した不確定性 パラメータの影響度を表すもので, 主 Sobol 係数は単体 の不確定性パラメータの影響度, 交互 Sobol 係数は複数 の不確定性パラメータの相互作用による影響度を示す.

本研究の不確定性パラメータは, 空力特性に大きく影 響すると考えられる風向角 $\alpha$ とレイノルズ数 Re とした.
表 1 に本研究の不確定性パラメータの範囲と不確定性の 確率分布を示す。一様分布と仮定したため $\mathrm{WSA}^{1)}$ より直 交多項式数列はルジャンドル多項式数列となる. 多項式 次数 2 次まで求めるものとする. 例えば, 2 次の多項式展 開をする場合は, 決定論的解析のサンプル点として 3 次 ルジャンドル多項式の零点を用い, 風向角 $\alpha$ とレイノル ズ数それぞれ 3 点ずつを組み合わせた計 9 回の決定論的 解析を実施する. 多項式次数 1 次, 2 次それぞれの決定論 的解析を行ならサンプル点を図 7 に示寸. QoI は, 前章 においてばらつきの幅が比較的案的していた全体力係数 と平均風圧係数とする.

\section{2 計算条件}

本研究ではLES を用い決定論的解析を行なう。計算領 域を図 8 , 計算条件を表 2 に示寸. 流入境界は一様流とし,

\begin{tabular}{|c|c|c|c|}
\hline & 不確定性 & 確率分布 & 区間 \\
\hline 角柱 & $\begin{array}{l}\text { 風向角 } \\
\text { レイノルズ数 }\end{array}$ & 一様分布 & $\begin{array}{l}{\left[12^{\circ}-14^{\circ}\right]} \\
{[1000-10000]}\end{array}$ \\
\hline 隅丸角柱 & $\begin{array}{l}\text { 風向角 } \\
\text { レイノズ数 }\end{array}$ & 一様分布 & $\begin{array}{l}{\left[5^{\circ}-7^{\circ}\right]} \\
{[1000-10000]}\end{array}$ \\
\hline
\end{tabular}
流出境界はノイマンで与えた。 上面と下面は Free-Slip 条 件とし，角柱表面はno-slip としている.

表 1 不確定性パラメータ

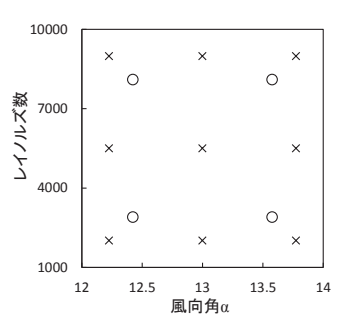

(a) 角柱

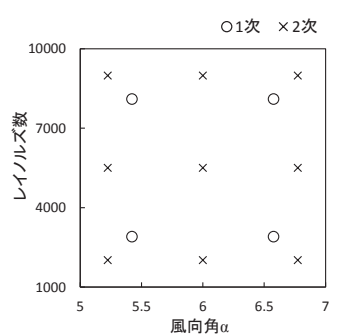

(b) 隅丸角柱
図 4 決定論的解析のサンプル点

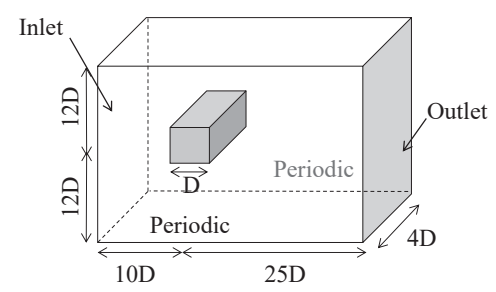

図 5 計算モデル

表 2 計算条件

\begin{tabular}{ll}
\hline コード & FrontFlowRed, FVM \\
\hline 計算格子 & 非構造格子 \\
空間離散化 & 2次中心差分 \\
& 2次中心差分 $(95 \%)+1$ 次風上 $(5 \%)($ 移流項 $)$ \\
\hline 時間積分 & SMAC, Euler陰解法 \\
\hline SGSモデル & Dynamic Smagorinsky model \\
\hline
\end{tabular}




\section{3 不確定性定量化結果}

表 3 に 1 次 $\cdot 2$ 次多項式における抗力係数 $\left(\mathrm{C}_{\mathrm{D}}\right)$ と揚力係 数 $\left(\mathrm{C}_{\mathrm{L}}\right)$ の確率論的平均と確率論的標準偏差を示寸. 抗力係 数の平均 $t$-ave $\left(C_{D}\right)$ においては, 平均, 標準偏差ともに 1 次・2 次多項式で推定された值が近く, 図 6 の確率分布も 比較的同様の傾向を示している. しかし，揚力係数の平 均 $t$-ave $\left(C_{L}\right)$ においては, 平均の值は比較的近いものの, 1 次における標準偏差は非常に小さい，本来であれば，平 均と標準偏差の収束が確認できるまで多項式次数を上げ るべきだが，計算コストの関係上，以降は 2 次多項式の 結果に基づいて議論をすすめる.

図 7 に角柱表面の平均風圧係数の平均と標淮偏差と

Sobol 係数を示す. 区間 CD では標準偏差が比較的大きい. これは風向角 $13^{\circ}$ 付近で, 前縁角部 D から剥離した流れ が再付着するか完全剥離するかの境目となっており, 再 付着の有無によって圧力の分布が大きく変わるため比較 的大きなばらつきを示している. Sobol 係数に関しては, CD 面においてはレイノルズ数が大きな值を示している. これは角部 D で剥離した流れの再付着の有無に接近流の 流速が大きく関わるためだと考えられる. 反対に完全剥 離流が発生する $\mathrm{AB}$ 面では風向角が大きな Sobol係数を示 すが，これは角柱の角部で剥離が固定されるため比較的 レイノルズ数の影響を受けにくく, 相対的に風向角の影 響が大きくなったと考えられる。

図 8 にいくつかのサンプル点における平均流を示して いる，風向角のみを変えた場合は $\mathrm{AB}$ 面における循環流 の位置や大きさの変化や, 後流域の構造に大きな影響を 与えていることが分かる. これら変化の様子は Sobol 係 数によって示されているものと一致している.

\section{4. 結論}

本研究では，まず流入条件のばらつきが空力特性のば らつきに与える影響を評価し，同時にばらつきの大きさ に格子解像度が与える影響を明らかにした，次に多項式 カオスを用いて簡易な形状モデルの空力特性における流 入条件の不確定性定量化を行った.

空力特性のばらつきは, 測定点位置や格子解像度, そ の空力特性の性質（平均值，ピーク值，積分値）により ばらつきの変化の傾向は異なることが確認された. PC を 用いた不確定性定量化では，わずかな流入条件のばらつ きが，空力特性に大きく影響することが確認され，今後 数值解を利用した設計時において不確定性を考慮するこ との重要性が示唆された. また風向角 $13^{\circ}$ 付近において 鋭敏に変化する流体現象の特徵を捉えることができ，本
研究ではPCが有効であったと考えられる.

表 3 角柱の抗力・揚力係数の確率論的平均と標準編差

\begin{tabular}{cccccc}
\hline & 多項式次数 & $t$-ave $\left(C_{D}\right)$ & $t$-std $\left(C_{D}\right)$ & $t$-ave $\left(C_{L}\right)$ & $t$-std $\left(C_{L}\right)$ \\
\hline \multirow{2}{*}{ 平均 } & 次数1 & 1.638 & 0.168 & -0.905 & 0.456 \\
& 次数2 & 1.672 & 0.174 & -0.822 & 0.489 \\
\hline \multirow{2}{*}{ 標準偏差 } & 次数1 & 0.059 & 0.012 & 0.031 & 0.105 \\
& 次数2 & 0.056 & 0.063 & 0.148 & 0.097 \\
\hline
\end{tabular}
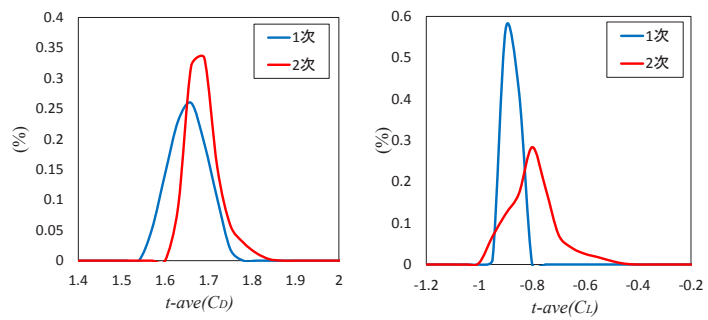

図 6 t-ave $\left(C_{D}\right)$ と $t$-ave $\left(C_{L}\right)$ の平均の確率分布
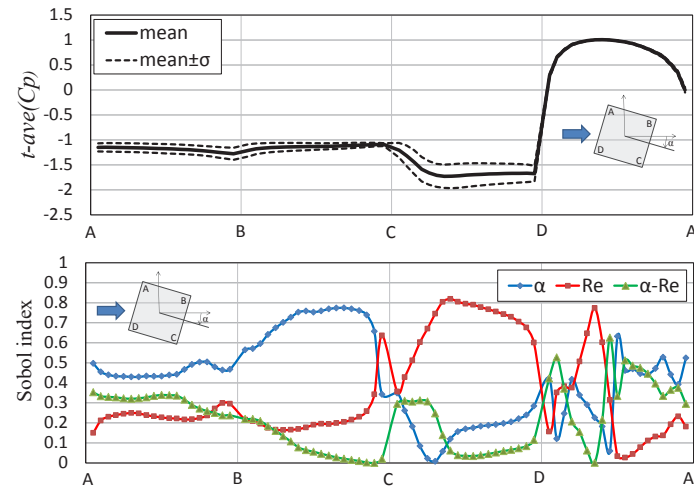

図 7 角柱の風圧係数の確率論的出力 (上) と Sobol 係数(下)

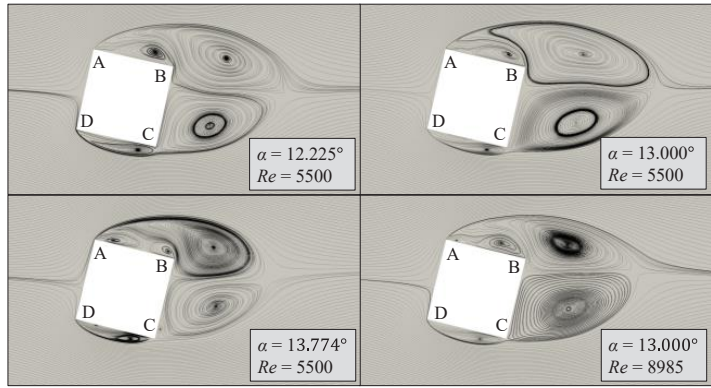

図 8 サンプル点における平均流（角柱）

参考文献

1) Xiu, Dongbin, and George Em Karniadakis. "Modeling uncertainty in steady state diffusion problems via generalized polynomial chaos." Computer methods in applied mechanics and engineering 191.43 (2002): 4927-4948.

2) Mariotti, Alessandro, Lorenzo Siconolfi, and MARIA VITTORIA Salvetti. "Stochastic sensitivity analysis of large-eddy simulation predictions of the flow around a 5: 1 rectangular cylinder." European Journal of Mechanics-B/Fluids 62 (2017): 149-165.

3) 田村哲郎, et al. "数値流体計算による実建築物の風荷重評価." 風工学シンポジウム論文集 第 24 回 風工学シンポジウム論文集.一般社団法人 日本風工学会, 2016 .

4) Jarrin, N., et al. "Reconstruction of turbulent fluctuations for hybrid RANS/LES simulations using a synthetic-eddy method." International Journal of Heat and Fluid Flow 30.3 (2009): 435-442.

5) Xu Wu, Chen Wang, Tomasz Kozlowski, "Kriging-based surrogate models for uncertainty quantification and sensitivity analysis." M\&C-2017, International Conference on mathematics \& Computaional method applied to Nuclear Science \& Engineering, Jeju, Korea (2107). 6)L.M.M. van den and Benjamin Sanderse, "Uncertainty quantification for wind energy applications Literature review." Centrum Wiskunde \& Information (2017), Report number: SC-1701.

7)Arun Kaintura, Tom Dhaene, Domenico Spina, "Review of polynomial chaos-based method for uncertainty quantification in modern integrated circuits" Journal of electronics 7/30 (2018); https://oi.org/10.3390/electronics 7030030

8)Bruno Sudret, "Global sensitivity analysis using polynomial chaos expansions.", Reliability Engineering \& System Safety 98.7 (2008); 964-979. 